\title{
Determinação do PCZ de adsorventes naturais utilizados na remoção de contaminantes em soluções aquosas.
}

\author{
Fernanda Beatriz Aires de Freitas* (Graduanda em Ciência e Tecnologia na Universidade Federal \\ Rural do Semi-árido, Caraúbas, RN) \\ Myrelle Yasmine de Freitas Câmara (Graduanda em Ciência e Tecnologia na Universidade \\ Federal Rural do Semi-árido, Caraúbas, RN) \\ Daniel Freitas Freire Martins (Docente do curso de Ciência e Tecnologia, Universidade Federal \\ Rural do Semi-árido, Caraúbas, RN) \\ *beatrizfernnanda@outlook.com
}

\section{Resumo:}

A contaminação da água por metais pesados e compostos orgânicos tem se tornado um problema grave para o meio ambiente. Dessa forma, torna-se cada vez mais frequente a busca por meios que possam reduzir essa poluição em meio aquoso. Dentre as diferentes formas de remoção de poluentes, se destaca a adsorção, que consiste em transferência de um ou mais constituintes de uma fase fluida para a superfície sólida. No processo de adsorção diversos materiais são usados como adsorventes e a sua caracterização é necessária para a aplicação adequada dos mesmos. Uma caracterização de extrema importância é o ponto de carga zero (PCZ), que indica o valor do $\mathrm{pH}$ que a superfície do material é neutra, ou seja, o pH é constante. A metodologia empregada para a determinação do PCZ é a do "experimento dos 11 pontos", onde se usa pH variando de 1,0 a 12. De modo que a adsorção do cátion é favorecida quando o pH da solução é maior que o PCZ, enquanto que a adsorção de ânions é favorecida quando $\mathrm{pH}$ é menor que o PCZ. Assim, este trabalho teve por objetivo determinar o ponto de carga zero do pó da casca de arroz, banana, coco, laranja, mamão, maracujá, melancia e melão. Os resultados encontrados foram de 5,38, 7,21, 4,43, 6,73, 5,36, 4,94, 6,05 e 6,31, respectivamente. Após analise e comparação dos resultados obtidos com outros trabalhos, foi possível perceber que todos os valores encontrados, estão de acordo com os encontrados na literatura em trabalhos realizados anteriormente. Portanto, o método utilizado é eficaz na determinação do ponto de carga zero dos materiais adsorventes.

\section{Palavras-chave:}

Adsorção; ponto de carga zero; experimento dos 11 pontos; variação de $\mathrm{pH}$; adsorventes naturais. 


\section{I NTRODUÇÃO}

Atualmente, a contaminação da água por metais pesados e compostos orgânicos tem se tornado um problema grave para o meio ambiente, pois em alta quantidade pode causar doenças e sérios danos à saúde dos seres vivos e comprometendo todo o ecossistema. Sendo assim, a busca por meios que reduzam essa concentração dessas substâncias nos efluentes líquidos são cada vez mais frequentes.

Essa contaminação é decorrente principalmente do elevado crescimento populacional e das atividades industriais (SILVA, 2012). Dessa forma, o setor têxtil destaca-se dentre as atividades industriais como um grande potencial poluente, devido o extenso parque industrial que gera grandes volumes de efluentes de composição extremamente heterogênea. Os métodos de tratamentos desses efluentes muitas vezes apresentam custo muito elevado e, em geral, produzem novos resíduos sem potencial de reaproveitamento, não proporcionando uma solução definitiva para o problema (KUNZ et al., 2002). Assim, busca-se o desenvolvimento de processos que sejam mais eficientes, e que gerem uma quantidade mínima de resíduos (NUNES, 2014).

Vários tratamentos são utilizados na indústria para à remoção de poluentes em meio aquoso, desde tratamentos biológicos a tratamento físico-químicos (MOHAN et al., 2008 apud NUNES, 2014). Entretanto, devido às desvantagens e inconvenientes dos tratamentos disponibilizados, a busca por tecnologias alternativas e mais eficientes se torna necessário. Com isso alguns métodos alternativos vêm sendo investigados.

Dentre os métodos mais empregados para descontaminação de efluentes contendo metais pesados, por exemplo, citam-se os processos de troca iônica, adsorção por carvão ativado, separação por membrana, processos biológicos, eletroquímicos e a neutralização/precipitação química (Gavallah e Kilbertus, 1998 apud MOREIRA, 2010), sendo a adsorção sólido/líquido uma das técnicas mais promissoras e efetivas na remoção de metais.

A adsorção é o processo de transferência de um ou mais constituintes de uma fase fluida para a superfície de uma fase sólida, onde o material inicial a ser adsorvido é o adsorbato e 0 material sólido onde ocorre a adsorção é chamado de adsorvente (BARROS e ARROYO, 2004). Caracteriza-se por ser um método simples que vem sendo bastante estudado para o tratamento de efluentes industriais (NUNES, 2008). A grande vantagem da adsorção é a baixa geração de resíduos, fácil recuperação das espécies adsorvidas e a possibilidade de reutilização dos adsorventes sem causar impactos ambientais (LIMA et al., 2008 apud NUNES, 2008).

Existem ainda alguns fatores que podem influenciar a adsorção como: a temperatura, a polaridade do solvente, velocidade de agitação, relação sólido-líquido, tamanho das partículas do sólido, concentração inicial do adsorvato, $\mathrm{pH}$ da solução, outras espécies competitivas e impurezas na superfície do adsorvente (SCHIMMEL, 2008).

Um fator de suma importância nos experimentos de adsorção é o efeito do $\mathrm{pH}$ do meio sobre a capacidade de adsorção dos cátions metálicos no biossorvente. Já que o pH do meio interfere na capacidade de adsorção dos biossorventes, devido a competição existente por sítios ativos e espécies protônicas e os íons metálicos (VAGHETTI, 2009).

Outro fator que também merece destaque nos processos adsortivos é o ponto de carga zero (PCZ). O ponto de carga zero ou $\mathrm{pH}$ do ponto de carga zero $\left(\mathrm{pH}_{\mathrm{PCZ}}\right)$ é definido como o $\mathrm{pH}$ em que a superfície do sólido possui carga neutra. O seu conhecimento permite prever a ionização de grupos funcionais de superficies e sua interação com espécies de metal em solução, como por exemplo, quando o sólido adsorvente é carregado negativamente em soluções de $\mathrm{pH}$ superior ao PCZ, poderá interagir com espécies metálicas positivas; já quando é carregado positivamente em soluçoes de $\mathrm{pH}$ inferior ao PCZ e poderá interagir com espécies negativas (FIOL; VILLAESCUSA, 2008 apud SILVA, 2012).

Além dos metais, corantes, sólidos suspensos, odores, matéria orgânica e óleos também podem ser removidos. O tipo de adsorvente mais utilizado no processo de adsorção industrial é o carvão ativado (LIN e LIU, 2000 apud MORAIS, 2007). No entanto, seu alto custo e dificuldade de regeneração limitam o seu uso (LENG e PINTO, 1996 apud MORAIS, 2007). Com isso, estudos laboratoriais estão sendo desenvolvidos com adsorventes alternativos de 
baixo custo, tais como restos de frutas, cascas de cereais (milho, arroz), resíduos industriais, argila, sílica, alumina, quitosana, etc. (WU et al. 2000 apud MORAIS,2007)

Assim, este trabalho teve por objetivo determinar o ponto de carga zero do pó da casca de arroz, banana, coco, laranja, mamão, maracujá, melancia e melão utilizados como adsorventes de diversos poluentes em sistemas aquosos.

\section{MATERI AIS E MÉTODOS}

A metodologia empregada para a determinação do ponto de carga zero é denominada por Regalbuto et al. (2014) como "experimento dos 11 pontos”. Os adsorventes utilizados para a análise foram casca de arroz, banana, coco, laranja, mamão, maracujá, melancia e melão (Figura 1).

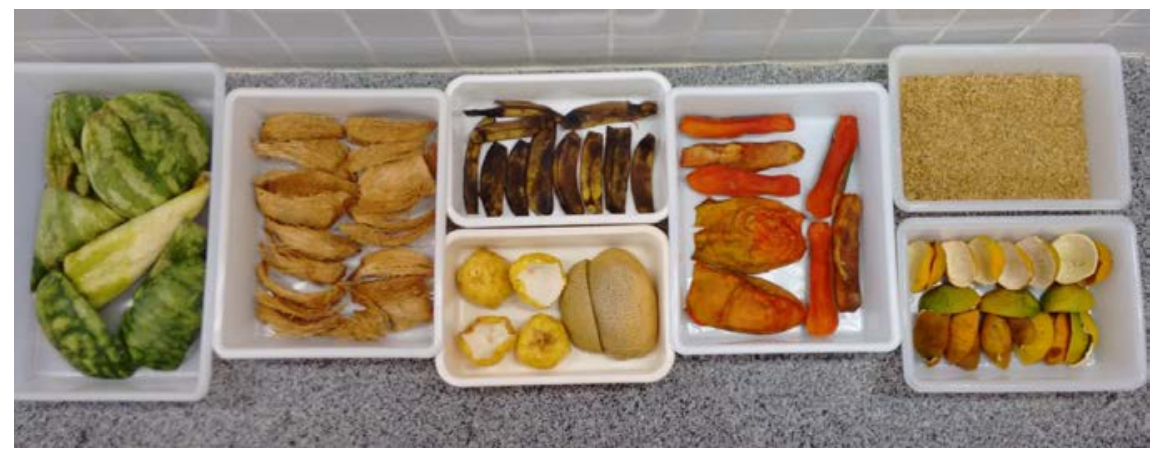

Figura 1 - casca de arroz, banana, coco, laranja, mamão, maracujá, melancia e melão

\subsection{Preparação do material adsorvente}

Primeiramente as cascas das frutas foram lavadas com o uso de água destilada. Após serem lavadas, as cascas foram secas em estufa (SOLAB) à $70^{\circ} \mathrm{C}$ por 24 horas, para eliminação total da umidade e, assim, atingissem a condição ideal para se triturar. Posteriormente, trituraram-se as mesmas em liquidificador da marca Mondial. Depois de trituradas, as cascas foram peneiradas utilizando uma peneira com $0,177 \mathrm{~mm}$ de abertura e marca GRANUTEST, obtendose assim um pó, como podemos ver na figura 2.

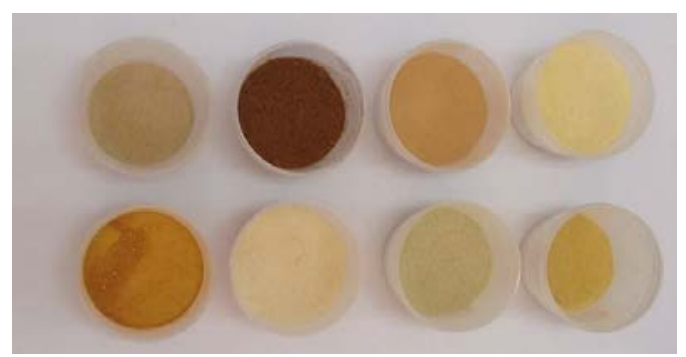

Figura 2 - Amostras trituradas e peneiradas.

\subsection{Preparação das soluções}

As soluções empregadas nos experimentos são de dois tipos: solução preparada a partir de $\mathrm{NaOH}$, da marca ALPHATEC, com 99\% de pureza e a partir de $\mathrm{HCl}$, da marca Dinâmica (Química contemporânea Ltda) 37\% as quais foram preparadas no Laboratório de Química da Universidade Federal Rural do Semi-Árido - UFERSA, Campus Caraúbas.

A preparação da primeira solução consistiu em adicionar 8,1 mL de $\mathrm{HCl}$ P.A. em um balão de volumétrico de $1 \mathrm{~L}$, completando o mesmo com água destilada. Obtendo-se assim uma solução de ácido clorídrico de $\mathrm{pH}$ 1, que a partir da sua diluição pode-se preparar soluções de pH 2, 3, 4, 5 e 6. A preparação da segunda solução consistiu em dissolver 0,4 g de $\mathrm{NaOH}$ em 
um pouco de água e em seguida adicionar a um balão volumétrico de $1 \mathrm{~L}$, completando o mesmo com água destilada. Com isso obtém-se uma solução de hidróxido de sódio de $\mathrm{pH} 12$, que a partir dela preparou-se soluções de pH 11, 10, 9 e 8.

\subsection{Determinação do Ponto de Carga Zero (PCZ)}

Para a determinação do ponto de carga zero foi-se pesado aproximadamente $50 \mathrm{mg}$ dos adsorventes e adicionado aos mesmos $50 \mathrm{~mL}$ de solução aquosa com valores de $\mathrm{pH}$ variando de 1,0 a 12 em béquer de $100 \mathrm{~mL}$, os quais foram transferidos para uma mesa agitadora (marca QUIMIS) sob agitação de 10 rpm, por 24 horas. Depois de 24 horas de equilíbrio mediu-se o pH final com o auxilio de um pHmetro de bancada (PHMETER JK-PHM-005) calibrado com soluções padrão de $\mathrm{pH} 4$ e de $\mathrm{pH}$ 7. Em seguida produziu-se os gráficos de $\mathrm{pH}$ inicial versus $\mathrm{pH}$ final para cada adsorvente, sendo que o PCZ de cada amostra foi obtido na faixa onde se observou o efeito tampão, ou seja, onde o $\mathrm{pH}$ não variou (independentemente do $\mathrm{pH}$ inicial). Desta forma, foi feito uma média aritmética dos valores de $\mathrm{pH}$ final que tendem aos mesmo valor para a determinação do PCZ.

\section{RESULTADOS E DISCUSSÃO}

O PCZ corresponde ao ponto que o $\mathrm{pH}$ se mantém constante, depois do sistema ter atingido o equilíbrio. Na tabela 1 é possível observar todos os valores encontrados para o $\mathrm{pH}$ dos materiais adsorventes. E assim se obter o gráfico 1 referente aos materiais em estudo.

Tabela 1 - Resultado dos ensaios da determinação do pH.

\begin{tabular}{ccccccccc}
\hline \multirow{2}{*}{$\begin{array}{c}\mathbf{p H} \\
\text { Inicial }\end{array}$} & \multicolumn{7}{c}{$\mathbf{p H}$ Final } \\
\cline { 2 - 9 } & Arroz & Banana & Coco & Laranja & Mamão & Maracujá & Melancia & Melão \\
\hline $\mathbf{1}$ & 1,89 & 1,78 & 0,51 & 1,88 & 1,90 & 1,17 & 1,04 & 0,59 \\
$\mathbf{2}$ & 2,75 & 2,70 & 1,42 & 2,74 & 2,78 & 1,99 & 1,94 & 1,51 \\
$\mathbf{3}$ & 3,65 & 4,00 & 2,63 & 4,00 & 4,23 & 3,14 & 3,61 & 2,97 \\
$\mathbf{4}$ & 5,08 & 5,1 & 3,73 & 5,53 & 4,33 & 3,97 & 5,43 & 5,58 \\
$\mathbf{5}$ & 5,28 & 6,08 & 4,10 & 6,55 & 4,64 & 4,36 & 5,84 & 5,71 \\
$\mathbf{6}$ & 5,45 & 6,58 & 4,33 & 6,79 & 5,22 & 4,75 & 5,97 & 5,77 \\
$\mathbf{8}$ & 5,72 & 7,12 & 4,60 & 6,86 & 5,38 & 4,95 & 6,05 & 7,04 \\
$\mathbf{9}$ & 8,57 & 7,19 & 4,83 & 7,27 & 5,30 & 5,02 & 6,19 & 6,86 \\
$\mathbf{1 0}$ & 8,26 & 7,22 & 4,97 & 7,68 & 5,35 & 5,05 & 6,27 & 6,54 \\
$\mathbf{1 1}$ & 7,93 & 7,33 & 6,00 & 7,56 & 6,34 & 5,75 & 6,59 & 6,64 \\
$\mathbf{1 2}$ & 9,80 & 10,09 & 7,46 & 9,88 & 8,25 & 10,15 & 8,74 & 8,88 \\
\hline
\end{tabular}




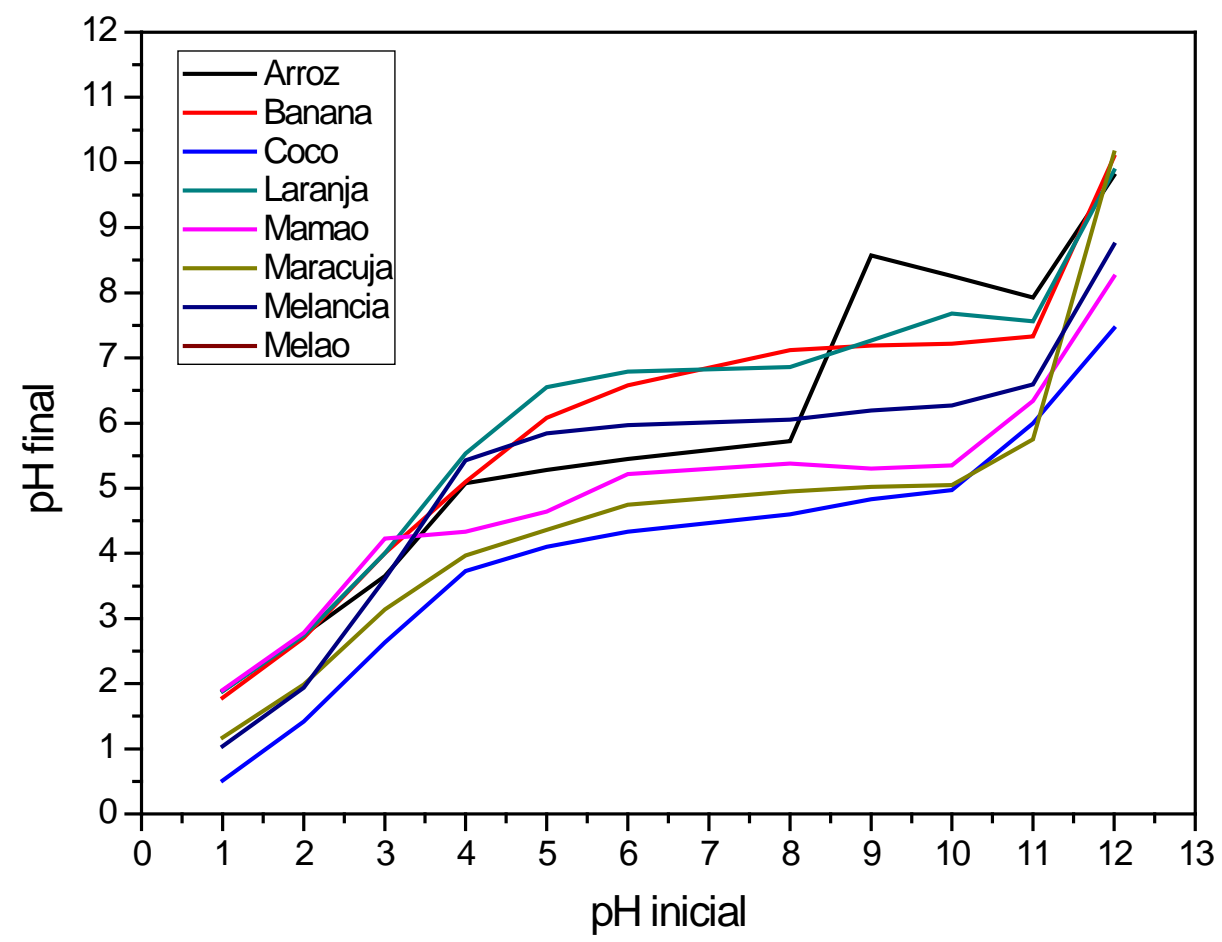

Gráfico 1 - Determinação do ponto de carga zero da casca de arroz, banana, coco, laranja, mamão, maracujá, melancia e melão

O gráfico 1 apresenta a relação entre o pH inicial e o final das soluções. A partir dai foi possível se calcular o ponto de carga zero fazendo-se uma média aritmética dos pontos que o $\mathrm{pH}$ final se mantêm constante. Os valores encontrados para os adsorventes utilizados estão dispostos na tabela 2 .

Tabela 2 - Resultado dos ensaios da determinação do PCZ.

\begin{tabular}{cc}
\hline & Ponto de Carga Zero (PCZ) \\
\hline Arroz & 5,38 \\
Banana & 7,21 \\
Coco & 4,43 \\
Laranja & 6,73 \\
Mamão & 5,36 \\
Maracujá & 4,94 \\
Melancia & 6,05 \\
Melão & 6,31 \\
\hline
\end{tabular}

Quando um material sólido entrar em contato com uma solução líquida com pH abaixo do PCZ, a superfície é carregada positivamente e um grande número de ânions é adsorvido para balancear as cargas positivas. Assim, os adsorventes são mais eficazes para a remoção, por exemplo, de materiais aniônicos (RIBEIRO et al., 2011).

Já em soluções aquosas com um pH mais alto do que o PCZ, a superfície é carregada negativamente e, adsorve, preferencialmente, cátions. Neste caso, os adsorventes são mais eficazes para a remoção de materiais catiônicos (RIBEIRO et al., 2011). 
Na tabela 2 encontram-se os pontos de carga zero da casca de arroz, banana, coco, laranja, mamão, maracujá, melancia e melão. No qual a adsorção do cátion é favorecida a um $\mathrm{pH}>\mathrm{PCZ}$, enquanto que a adsorção de ânions é favorecida quando $\mathrm{pH}<\mathrm{PCZ}$.

Resultados semelhantes também foram encontrado no trabalho de Ribeiro et al. (2011) para o arroz, no qual mostra que o ponto de carga zero de 5,3. Mostrando que abaixo desse valor de $\mathrm{pH}$ a superfície da matriz esta carregada positivamente com íons $\mathrm{H}^{+}$(favorável para a adsorção de ânions) e acima do $\mathrm{pH}$ a superfície está carregada negativamente com íons $\mathrm{OH}^{-}$ (favorável para a adsorção de cátions). É usado, por exemplo, para remoção do corante violeta brilhante remazol.

Segundo Paniagua et al. (2015), o ponto de carga zero da banana esta entre 5 e 8. Observando que em $\mathrm{pH}$ maior que 8 o material adsorvente apresenta-se negativamente carregada, enquanto que em $\mathrm{pH}$ menor que 5 , o material encontra-se positivamente carregado. Sendo que o PCZ encontrado no presente trabalho está entre esse intervalo.

Segundo Souza (2009), o PCZ para a casca do coco é de 4,1, sendo este uma alternativa econômica em meio aos adsorventes comerciais que possuem alto custo para produção, além de ser renovável e disponível. Dessa forma, o seu uso é de grande interesse ambiental, podendo adsorver corantes têxteis, como o turquesa remazol e azul remazol. Cambuim (2009) também realizou estudos sobre o coco, mostrando que o PCZ do mesmo é de 4,3. E ainda, que possui rápida adsorção em todas as espécies de ferro, adsorvendo 37,3\% em apenas cinco minutos de contato.

Sivaraja et al. (2001) apud Ströher (2008) utilizaram a casca de laranja para a realização de testes de adsorção na remoção de corante ácido, violeta 17 . Verificou-se em seus estudos que o pH mais favorável a adsorção foi de 6,3. Resultado coerente com o encontrado nesse trabalho que foi de 6,73. Assim a adsorção do corante ácido é favorecida em $\mathrm{pH}$ de solução acima do PCZ.

Vieira e Pavan (2010) estudaram a casca de mamão na remoção de íons cobre de solução aquosa, encontrando os melhores resultados de adsorção em pH 5,0. Ainda mostraram que a capacidade máxima de adsorção obtida pelo mamão é considerada bastante satisfatória quando comparadas com as capacidades máximas de adsorção de outros biossorventes citados na literatura para esse propósito, já que a cinética de adsorção é rápida, além de o adsorvente ser facilmente obtido e preparado. Sabe-se que o cobre é um cátion, assim a sua adsorção irá acontecer quando o pH da solução for maior que o PCZ, já que é onde a superfície é carregada negativamente e, adsorve cátions. $\mathrm{O}$ valor encontrado para o ponto de carga zero desse trabalho é de 5,36 que está na faixa de erro permitida, sendo assim coerente com o valor de pH 5 ideal na remoção de cátions.

Em estudo realizado por Caretta (2010) a farinha de casca de maracujá tem ponto de carga zero de 4,68. Mostra ainda que quando o pH da solução é igual ao PCZ, a somatória das cargas de superfície do adsorvente é nula e a força de atração eletrostática entre os cátions e a superfície do adsorvente é diminuída. Já quando o pH e o PCZ são diferentes, o equilíbrio é modificado. Adsorvendo íons metálicos em solução aquosa, sendo eles o chumbo (Pb), cádmio(Cd) e cobre $(\mathrm{Cu})$, de maneira rápida e barata. Portanto a casca de maracujá é ideal para a adsorção de cátions, ocorrendo em pH acima do PCZ.

Rauber et al. (2010) mostra que a casca da melancia pode ser usada para a adsorção de íons metálicos Cd (Cádmio) e que a sua adsorção depende do $\mathrm{pH}$ da solução, de modo que a quantidade adsorvida de íons $\mathrm{Cd}$ foi maior com o aumento do $\mathrm{pH}$ da solução até atingir a máxima adsorção em $\mathrm{pH}$ 8,7, mostrou ainda que a adsorção diminuiu com o aumento subsequente do $\mathrm{pH}$. A adsorção do cádmio acontece quando o $\mathrm{pH}$ da solução está acima do ponto de carga zero, que foi de 6,05 nesse trabalho, já que é onde ocorrerá a adsorção de cátions. Assim o resultado encontrado está coerente com o encontrado na literatura, pois sua máxima adsorção será em um ponto maior que o PCZ, como foi possível perceber nos resultados encontrados. 


\section{CONCLUSÃO}

Conclui-se que a contaminação da água por metais pesados e compostos orgânicos é um problema grave para o meio ambiente. Assim a busca de métodos para descontaminação desses ambientes é frequente, sendo a adsorção uma alternativa para esse problema. Para se obter uma adsorção eficiente é necessário se conhecer o material que será usado como adsorvente, destacando-se o ponto de carga zero, por permitir prever o $\mathrm{pH}$ ideal, ou seja, o $\mathrm{pH}$ ótimo do adsorvente utilizado se tendo maior eficiência na adsorção.

O ponto de carga zero (PCZ) dos materiais usados nesse trabalho foram de 5,38, 7,21, 4,43, 6,73, 5,36, 4,94, 6,05 e 6,31, para a casca de arroz, banana, coco, laranja, mamão, maracujá, melancia e melão respectivamente. Com esses valores é possível saber a maneira que se comporta o adsorvente, sendo que para valores de $\mathrm{pH}$ da solução menores do que o valor do PCZ a superfície do adsorvente é positiva, adsorvendo ânions e para valores de $\mathrm{pH}$ da solução maiores do que o PCZ a carga da superfície do adsorvente é negativa, adsorvendo cátions. Após analise e comparação dos resultados obtidos com outros trabalhos, foi possível perceber que todos os valores encontrados, estão de acordo com os encontrados na literatura, em trabalhos realizados anteriormente. Portanto, o método utilizado é eficaz na determinação do ponto de carga zero dos materiais adsorventes.

\section{PCZ Determination of natural adsorbents used in removing contaminants from aqueous solutions.}

\section{Abstract:}

The water contamination by heavy metals and organic compounds has become a serious problem to the environment. Thus, it becomes more common the search for ways that might reduce this pollution in water. Among the different ways of removing pollutants adsorption stands out, it consists of transfer of one or more constituents of a fluid phase to the solid surface. In the adsorption process, diverse materials are used as adsorbents and their characterization is required for proper application. The characterization of extreme importance is the point of zero charge ( $\mathrm{PZC}$ ), which indicates the $\mathrm{pH}$ value that is when the material surface is neutral, i.e., the $\mathrm{pH}$ is constant. The methodology for determining the PZC is the "experiment of 11 points," which use $\mathrm{pH}$ ranging from 1.0 to 12 . In order that the adsorption of cations is favored when the $\mathrm{pH}$ of the solution is greater than the PZC while the anion adsorption is favored when the $\mathrm{pH}$ is lower than PZC. This work aimed to determine the point of zero charge of the dust of rice husk, banana, coconut, orange, papaya, passion fruit, watermelon and cantaloupe. The results were 5.38, 7.21, 4.43, 6.73, 5.36, 4.94, 6.05 and 6.31 , respectively. After analyzing and comparing the results with other studies, was possible to realize that all the values obtained, are in line with those found in the literature on work done previously. Therefore, the methodology used is effective in determining the point of zero charge of the adsorbent material.

Keywords:

Adsorption; point of zero charge; experiment of 11 points; pH variation; natural adsorbents. 


\section{REFERENCI AS BI BLI OGRÁFI CAS}

BARROS, M. A. S.; ARROYO, P. A. Métodos de Remoção de Cromo de Águas Residuais. Métodos de Adsorção. Departamento de Engenharia Química/UEM, Maringá, PR, 2004.

CAMBUIM, K. B. Carvão de endocarpo de coco da baía ativado quimicamente com $\mathrm{H}_{3} \mathrm{PO}_{4}$ e fisicamente com vapor d'água: produção, caracterização e aplicação. 2009. 139f. Tese (Doutorado em Química Analítica). Universidade Federal da Paraíba, J oão Pessoa PB, 2009.

CARETTA, T. O. Avaliação do potencial das cascas de maracujá amarelo e de mexerica como biossorventes de metais pesados. 2010. 64f. Dissertação (Mestre em Química). Universidade Estadual de Londrina, Londrina, 2010.

KUNZ, A.; PERALTA-ZAMORA, P. Novas tendências no tratamento de efluentes têxteis. Química Nova, n. 25, p. 78-82, 2002.

MORAIS, W. A. Estudos de sorção de um corante aniônico modelo em partículas de quitosana reticulada. 2007. 109f. Dissertação (Mestre em Química). Universidade Federal do Rio Grande do Norte, Natal, 2007.

MOREIRA, D. R. Desenvolvimento de adsorventes naturais para tratamento de efluentes de galvanoplastia. 2010. 79f. Dissertação (Mestre em Engenharia e Tecnologia de Materiais). Pontifícia Universidade Católica do Rio Grande do Sul (PUCRS), Porto Alegre, 2010.

NUNES, A. S. Produção de adsorventes a partir da casca de amendoim visando a aplicação na remoção de corantes orgânicos. 2014. 66f. Dissertação (Mestre em Ciências Ambientais). Universidade Estadual do Sudoeste da Bahia (UESB), I tapetinga, 2014.

PANIAGUA, C.E.S.; BORGES, S.S.O.; COELHO, N.M.M. Estudo de caracterização da farinha da casca da banana na forma in natura e quimicamente modificada com tiosemicarbazida como biossorvente paraas (III). In: CONGRESSO BRASILEIRO DE QUÍMICA, 55., 2015. Goiânia. Anais... Goiânia/Goiás, 2015.

RAUBER, R.; CESTARI, C.; COSTA, K. C.; VASCONCELOS, H. L. Utilização de casca de melancia na adsorção do íon metálico Cd(II). In: CONGRESSO BRASILEIRO DE QUÍMICA, 50., 2010. Cuiabá. Anais... Cuiabá - MT, 2010.

REGALBUTO, J. R.; ROBLES, J. The engineering of Pt/Carbon Catalyst Preparation. University of Illinois: Chicago, 2004.

RIBEIRO, G. A. C.; SANTANA, S. A A.; BEZERRA, C. W. B.; SILVA, H. A. S.; VIEIRA, A. P. Casca de arroz in natura e tratada com ácido nítrico como adsorventes para remoçao do corante têxtil violeta brilhante remazol. In: CONGRESSO BRASILEIRO DE QUÍMICA, 51., 2011. São Luís. Anais... São Luís, 2011.

SCHIMMEL, D. Adsorção dos corantes reativos azul 5G e azul turquesa QG em carvão ativado comercial. 2008. 99f. Dissertação (Mestre em Engenharia Química). Universidade Estadual do Oeste do Paraná (UNI OESTE), Toledo - PR, 2008.

SILVA, M. V. R. Adsorção de cromo hexavalente por carvão ativado granulado comercial na presença de surfactante aniônico (LAS). 2012. 80f. Dissertação (Mestre em Engenharia Química). Universidade Federal do Pará, Belém, 2012.

SOUZA, J. L. Mesocarpo do coco verde (Cocos nucífera) como adsorvente para os corantes: turquesa remasol e azul remasol. 2009. 137f. Dissertação (Mestre em Química Analítica). Universidade Federal do Maranhão, São Luís - MA, 2009.

STRÖHER, A. P. Tratamento por adsorção em bagaço de laranja de um efluente da indústria têxtil. 2010. 80f. Dissertação (Mestre em Engenharia Química). Universidade Estadual de Maringá, Maringá - PR, 2010.

VAGHETTI, J. C. P. Utilização de Biossorventes para Remediação de Efluentes Contaminados por Í ons Metálicos. 2009. 99f. Tese (Doutorado em Química). Programa de Pós-Graduação em Química. Universidade Federal do Rio Grande do Sul, Porto Alegre, 2009.

VIEIRA, D. N.; PAVAN, F. Estudo da adsorção de cobre empregando mamão formosa como adsorvente. In: Salão Internacional de Ensino, Pesquisa e Extensão, 2010. 